\title{
Cholesterol, diabetes and major cardiovascular diseases in the Asia-Pacific region
}

\author{
Asia Pacific Cohort Studies Collaboration
}

Received: 30 March 2007 / Accepted: 19 July 2007 / Published online: 25 September 2007

(C) Springer-Verlag 2007

\begin{abstract}
Aims/hypothesis The aim of this study was to assess the association between total cholesterol and major cardiovascular diseases among persons with and without diabetes in the Asia-Pacific region.

Methods We used data on individual participants in 30 cohort studies from the Asia-Pacific region to compute the hazards ratios and $95 \%$ CIs for participants with and without diabetes at baseline, using Cox proportional models. Analyses were stratified by sex and region (Asia vs Australia or New Zealand) and adjusted for age. Repeat measurements of total cholesterol were used to adjust for regression dilution bias. Results The analysis included 333,533 individuals $(6.3 \%$ with diabetes at baseline) who experienced 6,074 fatal and non-fatal cardiovascular events over a median follow-up period of 4.0 years. Total cholesterol was positively associated with coronary heart disease (CHD) and ischaemic stroke, and negatively with haemorrhagic stroke in a continuous, log-linear fashion, similarly among participants with and without diabetes. Each $1 \mathrm{mmol} / 1$ increase above the 'usual' level for total cholesterol was associated with a $41 \%$ (95\% CI 23-63\%) and 42\% (95\% CI 35-50\%) greater risk of CHD among participants with and without diabetes. The
\end{abstract}

Electronic supplementary material The online version of this article (doi:10.1007/s00125-007-0801-2) contains details of all members of the Asia Pacific Cohort Studies Collaboration, which are available to authorised users.

Writing committee: A. P. Kengne, A. Patel, F. Barzi, K. Jamrozik, T. H. Lam, H. Ueshima, T. Ohkubo, X. H. Fang, H. C. Kim, M. Woodward.

Asia Pacific Cohort Studies Collaboration

The George Institute for International Health, University of Sydney,

P.O. Box M201, Level $10 \mathrm{KGV}$ Building, RPAH,

Missenden Road, Camperdown,

Sydney, New South Wales 2050, Australia

e-mail: apatel@george.org.au corresponding values for ischaemic stroke were $23 \%$ (95\% CI $0-52 \%)$ and $31 \%(95 \%$ CI $20-44 \%)$, respectively. These results were broadly consistent for sex, age and region.

Conclusions/interpretation Total cholesterol is associated with similarly increased risks of cardiovascular events in people with and without diabetes. While abnormal levels of other lipid fractions are frequently observed in people with diabetes, these data support aggressive lowering of total cholesterol and LDL-cholesterol levels for prevention of cardiovascular events.

Keywords Asia-Pacific · Cardiovascular diseases .

Cardiovascular risk $\cdot$ Cholesterol $\cdot$ Coronary heart disease .

Diabetes mellitus $\cdot$ Lipids $\cdot$ Stroke

$\begin{array}{ll}\text { Abbreviations } \\ \text { ANZ } & \text { Australia and New Zealand } \\ \text { APCSC } & \text { Asia Pacific Cohort Studies Collaboration } \\ \text { CVD } & \text { cardiovascular disease } \\ \text { HR } & \text { hazard ratio } \\ \text { ICD } & \text { International Classification of Diseases }\end{array}$

\section{Introduction}

The major importance of diabetes mellitus as an independent risk factor for cardiovascular disease (CVD) is well established and consistent across populations [1, 2]. Diabetes is associated with a two- to fourfold risk of cardiovascular events and cardiovascular death [3-5]. This excess risk associated with diabetes is partly attributable to a higher burden of major traditional cardiovascular risk factors, including non-optimal blood pressure, obesity and tobacco consumption, as well as dyslipidaemia $[4,6]$. The pattern of dyslipidaemia frequently observed in people with 
diabetes includes raised triacylglycerols, decreased levels of HDL-cholesterol and slightly raised or 'normal' plasma concentrations of LDL-cholesterol [6]. As a result, some have argued that to reduce risk of future cardiovascular events in people with diabetes, it may be more important to modify HDL-cholesterol and triacylglycerol levels than to lower total cholesterol or LDL-cholesterol levels.

The Asia Pacific Cohort Studies Collaboration (APCSC) is an individual participant data overview of prospective cohort studies conducted in a number of Asian countries, as well as Australia and New Zealand (ANZ). With several thousand events recorded, the Collaboration provides an opportunity to produce reliable evidence on the nature and size of the associations between risk factors and CVD, as well as a unique opportunity to compare these associations between Asian and non-Asian populations. The primary purpose of the current analyses was to determine whether total cholesterol was a less important marker of cardiovascular risk in people with than in people without diabetes. Secondary aims were to repeat these analyses within predefined age, sex and regional subgroups, and to explore the differential effects, according to diabetes status, of other lipid variables on coronary heart disease (CHD).

\section{Methods}

Participating studies The APCSC has been described in detail elsewhere [7]. In brief, studies were invited to join the Collaboration if they were based in the Asia-Pacific region, had information on age, sex and systolic blood pressure measured at baseline and at least 5,000 personyears of follow-up, with cause of death recorded during follow-up. Cohorts were classified as Asian if their participants were recruited from mainland China, Hong Kong, Japan, Korea, Singapore, Taiwan or Thailand; they were classified as ANZ if participants were recruited from Australia or New Zealand. All additional analyses conducted by the APCSC were approved by the University of Sydney Human Ethics Committee.

Measurement of baseline variables The presence of diabetes in individual participants was determined on the basis of a reported history of diabetes or by applying the 1999 WHO diagnostic criteria to blood glucose levels at baseline [8]. In one study that was included (Singapore National Health Survey) diabetes status was also determined by an oral glucose tolerance test. Measurements of lipids were determined using serum samples, these being obtained in the fasting state in most participants. As these studies were initiated over a long period of time, the methods and instruments used for measuring lipids varied. Detailed information on the method of cholesterol analysis was available from 23 studies comprising $72 \%$ of all participants; of these, 20 studies (29\% of participants with known methods of cholesterol assay) used enzymatic methods for cholesterol measurement. LDL-cholesterol was either directly measured or was calculated using Friedewald's formula [9], if the HDL-cholesterol level was available and the triacylglycerol value was $<4.4 \mathrm{mmol} / \mathrm{l}$. Approximately half the studies with HDL-cholesterol measurements reported using enzymatic methods; the remainder used precipitation. Triacylglycerol values were derived using enzymatic methods in most of the studies that reported this variable.

Outcomes All studies reported deaths by underlying cause; a subset of studies also reported non-fatal CVD events. Most studies used database linkage to identify deaths, while others also included scheduled follow-up visits or examined hospital records, particularly to identify non-fatal events. Outcomes were classified according to the Ninth Revision of the International Classification of Diseases (ICD-9). The fatal outcomes considered in this analysis were: CHD (ICD-9: 410 414); total stroke (430-438); haemorrhagic stroke (431.0 432.9); and ischaemic stroke (433.0-434.9). Non-fatal events were defined as those that did not result in death within 28 days. Because most studies identified events using record linkage, verification of subtype of stroke was not routinely reported; stroke subtype was assigned as 'unclassified' in the absence of this information. All data provided to the secretariat were checked for completeness and consistency and recoded, when necessary, to maximise comparability across cohorts. Summary reports were referred back to principal investigators of each collaborating study for review and confirmation.

Statistical methods All analyses used individual participant data and were restricted to individuals who were aged $>20$ years with information on diabetes status and total cholesterol measurement at the time of baseline survey. To determine the association between the 'usual' level of total cholesterol and the outcome of interest, estimates were adjusted to account for regression dilution bias. Repeat measures of fasting total cholesterol, on up to seven occasions between 2 and 30 years after the baseline measurement were available from eight studies. These repeat measures were used to estimate the attenuation coefficient using a linear mixed regression model that accounted for the heterogeneity of variance between studies, within-subject correlation and the varying time intervals between measurements. For grouped analysis, individuals were classified according to approximately equal fourths of total cholesterol as assessed at baseline for the entire study population $(<4.5,4.5-5,5.1-5.6$ and $>5.6 \mathrm{mmol} / \mathrm{l})$.

We used Cox proportional hazard regression models to estimate hazard ratios (HRs), with corresponding 95\% CIs calculated using the 'floating absolute risk' method [10]. 
Log-linearity of the associations with the outcomes was explored through analyses by fourths and summarised through the HR (and 95\% CI) for a difference of $1 \mathrm{SD}$ in the usual level of total cholesterol. The statistical significance of an interaction between total cholesterol and diabetes status was assessed using likelihood ratio tests to compare the models, including main effects only with models that also included the interaction terms between total cholesterol and diabetes. Results were derived for all included individuals, as well as for pre-defined subgroups defined by region (Asia vs ANZ), age ( $<65$ years vs $\geq 65$ years) and sex [7]. Tests for three-way interaction between diabetes, total cholesterol and the pre-defined subgroups were also performed for each of the outcomes. All the Cox models were adjusted by age and sex (when appropriate) and stratified by study. As a sensitivity analysis, we also examined the associations between total cholesterol and each outcome among participants with and without diabetes after excluding the two largest studies, which together contributed more than half the events.

For the subset of participants in whom data on baseline HDL-cholesterol and triacylglycerols were available, we also examined the associations between the following lipid variables and CHD for people with and without diabetes: LDL-cholesterol, HDL-cholesterol, non-HDL-cholesterol (difference between total cholesterol and HDL-cholesterol) and triacylglycerols (after log transformation to account for right skewness). Due to limited power, we were unable to reliably evaluate these associations for stroke subtypes and among subgroups of participants.

\section{Results}

Available data By April 2006, information on diabetes status and total cholesterol measurements at baseline were available from 30 studies, involving 333,533 individuals with 2,056,867 person-years of follow-up (Table 1). These 30 studies represented $56 \%$ of the entire APCSC study population. In addition, 21 cohorts with 62,493 participants had baseline data available for calculated LDL-cholesterol.

Baseline variables Among the 333,533 participants included, $21,116(6.3 \%)$ were classified as having diabetes at baseline: 17,867 (7.1\%) in Asia and 3,249 (4.0\%) in ANZ (Table 1). Overall, participants with diabetes were older (51 [SD 10] years vs 47 [10] years, $p<0.0001)$ and were more likely to be male $(60.1$ vs $48.4 \%, p<0.0001)$ and to have higher levels of total cholesterol (5.34 [1.09] vs 5.11 [1.02] $\mathrm{mmol} / 1, p<0.0001)$. Similar differences were also observed when the Asian and ANZ cohorts were examined separately.

Outcomes The median follow-up was 4.0 years in the overall study population and among participants with and without diabetes (Table 2). In addition to information on fatal events that was available from all cohorts (1,953 CHD deaths, 1,508 stroke deaths), data on non-fatal events (i.e. those not followed by a fatal event) were available from ten studies for CHD (746 events) and 12 studies for stroke (1,867 events). Thus, during follow-up, 2,699 CHD events and 3,375 strokes were recorded. The proportion of cardiovascular events due to CHD was similar in people with (41.5\%) and without diabetes (44.8\%). Subclassification of stroke as ischaemic or haemorrhagic subtypes was provided for 59.6 and $58.0 \%$ of all cases of stroke in people with and without diabetes, respectively. Among all classified strokes, $65.8 \%$ in participants with diabetes and $42.9 \%$ in those without diabetes were haemorrhagic. The corresponding figures for fatal classified strokes were 61.4 and $54.5 \%$, respectively. Stroke represented $74.4 \%$ of cardiovascular outcomes in Asia, whereas CHD predominated in ANZ, accounting for $63.2 \%$ of cardiovascular events. The agestandardised incidence of CHD events (per 10,000 personyears) was 21.3 (95\% CI 18.7-23.9) for participants with and 12.6 (95\% CI 12.1-13.1) for participants without diabetes. The corresponding incidence rates for ischaemic stroke were 12.2 (95\% CI 10.2-14.2) and 5.1 (95\% CI 4.85.4) and for haemorrhagic stroke, 6.8 (95\% CI 5.2-8.4) and $3.8(95 \%$ CI 3.6-4.1).

Overall associations between total cholesterol and major cardiovascular outcomes Total cholesterol was associated with the risk of CHD and stroke in a continuous log-linear fashion in participants with and without diabetes (Fig. 1). While this association was always positive for CHD and ischaemic stroke events, a negative association was observed for the risk of haemorrhagic stroke associated with total cholesterol. Overall the strength of the association between total cholesterol and the risk of major cardiovascular events was similar for people with and without diabetes. Thus, for each increase of $1 \mathrm{SD}(1 \mathrm{mmol} / \mathrm{l})$ in total cholesterol, participants with diabetes had a 41\% (95\% CI 23-63\%) greater risk of a CHD; the corresponding estimate for participants without diabetes was $42 \%$ (95\% CI 35-50\%) ( $p=0.93$ for interaction). For ischaemic stroke, each $1 \mathrm{mmol} / \mathrm{l}$ increase of total cholesterol was associated with a $23 \%$ (95\% CI 0 $52 \%$ ) greater risk among people with diabetes and a $31 \%$ (95\% CI 20-44\%) greater risk for individuals without diabetes ( $p=0.60$ for interaction). The corresponding values for haemorrhagic stroke were a 37\% (95\% CI 5-53\%) and a $13 \%$ (95\% CI 1-23\%) lower risk for people with and without diabetes, respectively ( $p=0.16$ for interaction). When unclassified stroke was examined, there was borderline evidence of heterogeneity in the association with total cholesterol in people with and without diabetes (HR for $1 \mathrm{mmol} / 1$ increase of total cholesterol: 1.29 [95\% CI 1.071.56] vs 1.06 [95\% CI $0.97-1.15], p=0.05$ for interaction). 
Table 1 Study characteristics by diabetes status at baseline

Study name by region Baseline data No diabetes

\begin{tabular}{|c|c|c|c|}
\hline$n$ & Age (years) & $\begin{array}{l}\text { Total } \\
\text { cholesterol } \\
(\mathrm{mmol} / \mathrm{l})\end{array}$ & Female $\%$ \\
\hline & Mean SD & Mean SD & \\
\hline
\end{tabular}

Diabetes

\begin{tabular}{llll}
\hline$n \quad$ Age (years) & $\begin{array}{l}\text { Total } \\
\text { cholesterol } \\
(\mathrm{mmol} / \mathrm{l})\end{array}$ & \\
\hline Mean $\quad$ SD & Mean SD & \\
\hline
\end{tabular}

\begin{tabular}{|c|c|c|c|c|c|c|c|c|c|c|c|c|c|}
\hline \multicolumn{14}{|l|}{ Asia } \\
\hline Aito Town ${ }^{\mathrm{a}}$ & 1980-1983 & 1,626 & 51 & 9 & 4.63 & 0.85 & 57.6 & 45 & 55 & 9 & 4.80 & 0.97 & 22.2 \\
\hline Akabane $^{a}$ & 1985-1986 & 1,789 & 54 & 8 & 4.98 & 0.91 & 56.1 & 45 & 57 & 8 & 5.27 & 1.04 & 40.0 \\
\hline Anzhen $02^{\mathrm{a}}$ & 1992-1993 & 3,678 & 47 & 8 & 4.69 & 0.86 & 51.9 & 461 & 50 & 8 & 4.96 & 0.93 & 43.6 \\
\hline Beijing Aging ${ }^{a}$ & 1992 & 1,195 & 69 & 9 & 4.32 & 1.02 & 50.8 & 497 & 69 & 8 & 4.43 & 1.05 & 49.3 \\
\hline $\begin{array}{l}\text { Civil Service } \\
\text { Workers }^{\mathrm{a}}\end{array}$ & 1990-1992 & 9,143 & 47 & 5 & 5.18 & 0.92 & 33.4 & 161 & 49 & 4 & 5.44 & 0.96 & 19.3 \\
\hline CVDFACTS $^{\mathrm{a}}$ & 1988-1996 & 5,397 & 47 & 15 & 4.94 & 1.17 & 55.8 & 144 & 60 & 11 & 5.39 & 1.16 & 46.5 \\
\hline EGAT $^{\mathrm{a}, \mathrm{b}}$ & 1985 & 3,393 & 43 & 5 & 5.76 & 1.11 & 23.1 & 98 & 46 & 5 & 6.03 & 1.27 & 10.2 \\
\hline Fangshan $^{\mathrm{a}}$ & 1992 & 754 & 47 & 9 & 4.55 & 1.05 & 67.1 & 58 & 50 & 10 & 5.07 & 0.92 & 72.4 \\
\hline $\begin{array}{l}\text { Guangzhou } \\
\text { Occupational }^{\mathrm{a}}\end{array}$ & 1985-1995 & 4,505 & 44 & 7 & 5.32 & 1.13 & 32.7 & 457 & 46 & 8 & 5.67 & 1.29 & 30.2 \\
\hline Hong Kong ${ }^{\mathrm{a}}$ & 1991 & 174 & 79 & 7 & 5.25 & 0.92 & 50.0 & 21 & 79 & 5 & 5.31 & 1.10 & 66.7 \\
\hline Huashan $^{\mathrm{a}}$ & 1990-1992 & 1,611 & 53 & 12 & 4.61 & 0.89 & 52.1 & 194 & 59 & 10 & 4.93 & 0.95 & 51.5 \\
\hline KMIC & 1992 & 169,474 & 44 & 7 & 4.95 & 0.85 & 38.8 & 14,109 & 47 & 7 & 5.29 & 1.03 & 15.0 \\
\hline Konan $^{a}$ & 1987-1995 & 1,065 & 50 & 16 & 4.85 & 0.85 & 56.4 & 155 & 62 & 13 & 5.10 & 0.93 & 47.7 \\
\hline Ohasama $^{\mathrm{a}}$ & 1992-1993 & 1,724 & 58 & 11 & 5.00 & 0.87 & 66.8 & 183 & 61 & 10 & 5.05 & 0.88 & 45.9 \\
\hline Saitama & 1986-1990 & 3,562 & 54 & 12 & 4.99 & 0.96 & 62.4 & 61 & 62 & 8 & 5.31 & 0.78 & 52.5 \\
\hline $\begin{array}{l}\text { Seven Cities } \\
\text { Cohorts }^{\mathrm{a}}\end{array}$ & 1987 & 6,227 & 58 & 10 & 5.03 & 1.47 & 57.0 & 101 & 58 & 7 & 5.59 & 1.66 & 59.4 \\
\hline Shibata & 1977 & 2,303 & 57 & 11 & 4.61 & 1.21 & 57.7 & 25 & 61 & 11 & 4.72 & 1.10 & 48.0 \\
\hline Shigaraki Town ${ }^{a}$ & 1991-1997 & 3,481 & 57 & 14 & 5.00 & 0.90 & 60.8 & 269 & 65 & 11 & 5.02 & 0.97 & 42.8 \\
\hline Shirakawa & 1974-1979 & 4,601 & 48 & 12 & 4.63 & 0.94 & 54.3 & 42 & 50 & 13 & 4.71 & 0.86 & 57.1 \\
\hline Singapore Heart ${ }^{\mathrm{a}, \mathrm{b}}$ & 1982-1997 & 2,030 & 39 & 13 & 5.80 & 1.23 & 50.0 & 265 & 52 & 13 & 6.32 & 1.35 & 42.6 \\
\hline Singapore NHS92 $2^{\mathrm{a}, \mathrm{b}}$ & 1989-1990 & 2,983 & 38 & 12 & 5.29 & 1.02 & 51.8 & 320 & 51 & 11 & 5.97 & 1.10 & 51.6 \\
\hline Tanno/Soubetsu & 1977 & 1,831 & 51 & 7 & 4.92 & 0.99 & 53.0 & 142 & 54 & 7 & 5.26 & 1.08 & 55.6 \\
\hline Yunnan & 1992-1993 & 2,612 & 54 & 9 & 4.31 & 0.79 & 3.9 & 14 & 54 & 7 & 4.69 & 0.84 & 7.1 \\
\hline Total Asia & 1974-1997 & 235,158 & 46 & 8.9 & 4.96 & 0.92 & 41.3 & 17,867 & 49 & 9 & 5.28 & 1.07 & 21.0 \\
\hline \multicolumn{14}{|l|}{ ANZ } \\
\hline $\operatorname{ALSA}^{\mathrm{a}, \mathrm{b}}$ & 1992-1993 & 1,065 & 78 & 6 & 5.86 & 1.15 & 49.1 & 85 & 79 & 6 & 5.58 & 1.16 & 31.8 \\
\hline Busselton $^{a}$ & 1966-1981 & 5,509 & 46 & 16 & 5.87 & 1.29 & 52.5 & 204 & 58 & 16 & 6.17 & 1.33 & 45.1 \\
\hline Fletcher Challenge & 1992-1994 & 9,999 & 44 & 15 & 5.35 & 1.15 & 27.8 & 265 & 56 & 15 & 5.71 & 1.16 & 31.7 \\
\hline Melbourne & 1990-1994 & 38,920 & 55 & 9 & 5.52 & 1.05 & 59.7 & 2,221 & 59 & 7 & 5.65 & 1.13 & 45.7 \\
\hline Newcastle & 1988-1994 & 3,289 & 53 & 11 & 5.78 & 1.09 & 50.3 & 119 & 60 & 9 & 5.67 & 1.01 & 32.8 \\
\hline NHFA $^{a}$ & 1989-1990 & 8,948 & 43 & 13 & 5.52 & 1.13 & 50.8 & 162 & 55 & 12 & 5.78 & 1.14 & 40.7 \\
\hline Perth $^{\mathrm{a}, \mathrm{b}}$ & 1978-1994 & 9,529 & 45 & 13 & 5.78 & 1.22 & 47.3 & 193 & 52 & 13 & 5.63 & 1.21 & 49.2 \\
\hline Total ANZ & 1966-1994 & 77,259 & 50 & 13 & 5.57 & 1.13 & 51.9 & 3,249 & 59 & 10 & 5.69 & 1.15 & 43.6 \\
\hline Total & 1966-1997 & 312,417 & 47 & 10 & 5.11 & 1.02 & 51.6 & 21,116 & 51 & 10 & 5.34 & 1.09 & 39.9 \\
\hline
\end{tabular}

All data included in the table are taken from the ASPSC database

${ }^{a}$ HDL-cholesterol, triacylglycerols and calculated LDL-cholesterol available

${ }^{\mathrm{b}}$ Directly measured LDL-cholesterol available

ALSA, Australian Longitudinal Study of Aging; CVDFACTS, The Cardiovascular Disease Risk Factors Two-Township Study; EGAT, Electricity Generating Authority of Thailand Study; KMIC, Korean Medical Insurance Corporation Study; NHFA, National Heart Foundation of Australia; NHS92, National Health Study 1992

Subgroup analyses There was no evidence of any heterogeneity in the association between total cholesterol and CHD events among people with and without diabetes, when analyses were stratified by region, sex or age (Figs. 2 and 3). Absence of heterogeneity in the associations among subgroups was also observed for ischaemic and haemorrhagic stroke, with the exception of regional comparisons (Fig. 3). Among participants from ANZ cohorts, there was some evidence of heterogeneity in the association between total cholesterol and both haemorrhagic stroke $(p=0.03)$ 
Table 2 Fatal and non-fatal cardiovascular events by diabetes status

\begin{tabular}{|c|c|c|c|c|c|c|c|c|c|c|c|c|}
\hline \multirow{3}{*}{$\begin{array}{l}\text { Study name by } \\
\text { region }\end{array}$} & \multicolumn{6}{|c|}{ No diabetes } & \multicolumn{6}{|l|}{ Diabetes } \\
\hline & \multirow{2}{*}{$\begin{array}{l}\text { Median } \\
\text { follow- } \\
\text { up }\end{array}$} & \multirow{2}{*}{$\begin{array}{l}\text { Person- } \\
\text { years }\end{array}$} & \multirow[t]{2}{*}{ CHD } & \multicolumn{3}{|l|}{ Stroke } & \multirow{2}{*}{$\begin{array}{l}\text { Median } \\
\text { follow- } \\
\text { up }\end{array}$} & \multirow{2}{*}{$\begin{array}{l}\text { Person- } \\
\text { years }\end{array}$} & \multirow[t]{2}{*}{ CHD } & \multicolumn{3}{|l|}{ Stroke } \\
\hline & & & & Haem. & Ischaemic & Unknown & & & & Haem. & Ischaemic & Unknown \\
\hline \multicolumn{13}{|l|}{ Asia } \\
\hline Aito Town ${ }^{\mathrm{a}}$ & 15.2 & 24355 & 14 & 5 & 0 & 18 & 16.4 & 665 & 1 & 0 & 0 & 1 \\
\hline Akabane $^{\mathrm{a}}$ & 11.0 & 19983 & 26 & 5 & 15 & 17 & 11.0 & 463 & 2 & 1 & 0 & 0 \\
\hline Anzhen $02^{\mathrm{a}}$ & 3.0 & 10490 & 1 & 1 & 10 & 1 & 3.0 & 1308 & 0 & 4 & 0 & 0 \\
\hline $\begin{array}{l}\text { Beijing } \\
\text { Aging }^{\mathrm{a}}\end{array}$ & 4.8 & 5270 & 0 & 0 & 0 & 45 & 4.7 & 2144 & 0 & 0 & 0 & 22 \\
\hline $\begin{array}{l}\text { Civil Service } \\
\text { Workers }^{\mathrm{a}}\end{array}$ & 6.7 & 59500 & 1 & 1 & 0 & 1 & 6.5 & 982 & 0 & 0 & 0 & 0 \\
\hline CVDFACTS $^{\mathrm{a}}$ & 6.0 & 34683 & 10 & 6 & 7 & 10 & 5.8 & 859 & 2 & 0 & 2 & 4 \\
\hline $\mathrm{EGAT}^{\mathrm{a}, \mathrm{b}}$ & 11.4 & 34287 & 26 & 0 & 0 & 14 & 11.4 & 802 & 7 & 0 & 0 & 2 \\
\hline Fangshan $^{\mathrm{a}}$ & 2.7 & 2030 & 2 & 1 & 5 & 1 & 2.7 & 158 & 0 & 0 & 0 & 0 \\
\hline $\begin{array}{l}\text { Guangzhou } \\
\text { Occupational }^{\mathrm{a}}\end{array}$ & 7.7 & 35825 & 5 & 5 & 0 & 0 & 8.0 & 3639 & 0 & 0 & 0 & 0 \\
\hline Hong Kong $^{\mathrm{a}}$ & 2.5 & 380 & 7 & 0 & 0 & 4 & 2.5 & 43 & 0 & 0 & 0 & 0 \\
\hline Huashan $^{\mathrm{a}}$ & 2.8 & 4049 & 3 & 5 & 9 & 0 & 2.8 & 468 & 0 & 1 & 1 & 0 \\
\hline KMIC & 4.0 & 674786 & 252 & 321 & 392 & 302 & 4.0 & 55703 & 63 & 101 & 59 & 46 \\
\hline Konan $^{a}$ & 6.4 & 6764 & 2 & 2 & 4 & 2 & 6.2 & 907 & 0 & 3 & 1 & 0 \\
\hline Ohasama $^{\mathrm{a}}$ & 4.1 & 7162 & 4 & 10 & 22 & 5 & 4.1 & 757 & 0 & 5 & 0 & 0 \\
\hline Saitama & 11.0 & 36192 & 23 & 14 & 25 & 13 & 10.0 & 574 & 1 & 2 & 1 & 0 \\
\hline $\begin{array}{l}\text { Seven Cities } \\
\text { Cohorts }^{\mathrm{a}}\end{array}$ & 2.7 & 35208 & 63 & 120 & 95 & 1 & 2.7 & 354 & 2 & 5 & 3 & 0 \\
\hline Shibata & 20.0 & 36817 & 67 & 35 & 72 & 90 & 15.3 & 332 & 0 & 3 & 1 & 2 \\
\hline $\begin{array}{c}\text { Shigaraki } \\
\text { Town }^{\mathrm{a}}\end{array}$ & 4.4 & 13489 & 1 & 1 & 4 & 7 & 3.4 & 1041 & 2 & 0 & 1 & 0 \\
\hline Shirakawa & 17.5 & 76608 & 65 & 30 & 37 & 17 & 16.5 & 663 & 0 & 2 & 1 & 0 \\
\hline $\begin{array}{l}\text { Singapore } \\
\text { Heart }^{\mathrm{a}, \mathrm{b}}\end{array}$ & 14.7 & 25648 & 42 & 6 & 17 & 25 & 12.7 & 2596 & 19 & 5 & 1 & 18 \\
\hline $\begin{array}{l}\text { Singapore } \\
\text { NHS92 }^{\mathrm{a}, \mathrm{b}}\end{array}$ & 6.2 & 18411 & 19 & 3 & 8 & 13 & 6.2 & 1909 & 14 & 6 & 1 & 13 \\
\hline $\begin{array}{l}\text { Tanno/ } \\
\text { Soubetsu }\end{array}$ & 16.4 & 27982 & 21 & 14 & 9 & 7 & 16.4 & 2141 & 3 & 1 & 2 & 0 \\
\hline Yunnan & 4.5 & 11592 & 5 & 23 & 4 & 0 & 4.4 & 59 & 0 & 0 & 0 & 0 \\
\hline Total Asia & 4.0 & 1201510 & 659 & 608 & 735 & 593 & 4.0 & 78568 & 116 & 139 & 74 & 108 \\
\hline \multicolumn{13}{|l|}{ ANZ } \\
\hline $\operatorname{ALSA}^{\mathrm{a}, \mathrm{b}}$ & 4.8 & 5260 & 53 & 8 & 4 & 20 & 3.6 & 378 & 7 & 0 & 0 & 3 \\
\hline Busselton $^{\mathrm{a}}$ & 23.8 & 136341 & 909 & 74 & 173 & 436 & 19.1 & 3420 & 56 & 8 & 1 & 21 \\
\hline $\begin{array}{l}\text { Fletcher } \\
\text { Challenge }\end{array}$ & 5.8 & 57056 & 240 & 9 & 59 & 101 & 5.6 & 1446 & 30 & 7 & 0 & 12 \\
\hline Melbourne & 8.5 & 333604 & 272 & 29 & 9 & 44 & 9.2 & 19416 & 51 & 2 & 6 & 9 \\
\hline Newcastle & 5.6 & 19736 & 38 & 3 & 0 & 3 & 3.4 & 631 & 4 & 0 & 0 & 2 \\
\hline NHFA $^{\mathrm{a}}$ & 8.3 & 73328 & 72 & 0 & 1 & 12 & 8.3 & 1274 & 5 & 0 & 0 & 3 \\
\hline Perth $^{\mathrm{a}, \mathrm{b}}$ & 14.4 & 123272 & 174 & 10 & 4 & 42 & 8.1 & 1629 & 13 & 0 & 0 & 3 \\
\hline Total ANZ & 8.4 & 748596 & 1758 & 133 & 250 & 658 & 8.6 & 28193 & 166 & 17 & 7 & 53 \\
\hline Total & 4.0 & 1950106 & 2417 & 741 & 985 & 1251 & 4.0 & 106761 & 282 & 156 & 81 & 161 \\
\hline
\end{tabular}

All data included in the table are taken from the ASPSC database

${ }^{\text {a }}$ HDL-cholesterol, triacylglycerols and calculated LDL-cholesterol available

${ }^{\mathrm{b}}$ Directly measured LDL-cholesterol available

ALSA, Australian Longitudinal Study of Aging; CVDFACTS, The Cardiovascular Disease Risk Factors Two-Township Study; EGAT, Electricity Generating Authority of Thailand Study; Haem, haemorrhagic; KMIC, Korean Medical Insurance Corporation Study; NHFA, National Heart Foundation of Australia; NHS92, National Health Study 1992 

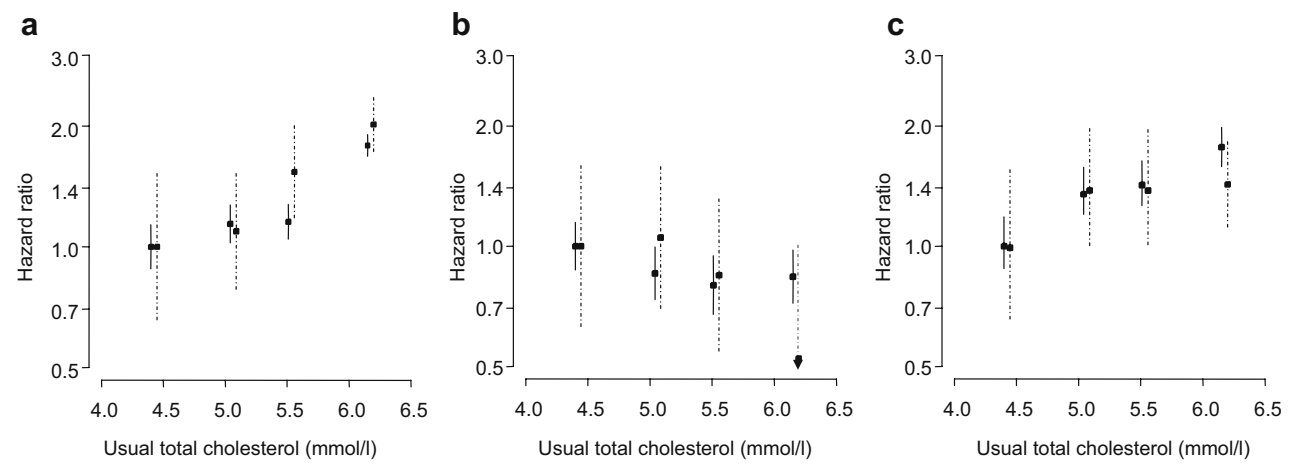

Fig. 1 Association between usual total cholesterol and CHD (a), haemorrhagic stroke (b) and ischaemic stroke (c) for participants with and without diabetes at baseline. The HR for the lowest fourth of total cholesterol was fixed at 1.0, separately for participants with and without diabetes. Analyses were adjusted by age and stratified by study and sex for participants with and without diabetes. $p=0.93$ (a), $p=0.16$ (b) and $p=0.60$ (c) for heterogeneity of the association of total cholesterol and major outcomes by diabetes status. Dashed lines, $95 \%$ CI with diabetes; continuous lines, 95\% CI without diabetes; arrowhead, lower 95\% CI spans beyond the $x$-axis and ischaemic stroke $(p=0.05)$ for persons with and without diabetes. However, these analyses included very few events (e.g. only seven haemorrhagic strokes among people with diabetes in the ANZ cohorts); moreover, for all subgroup analyses, the three-way test for interaction was nonsignificant.

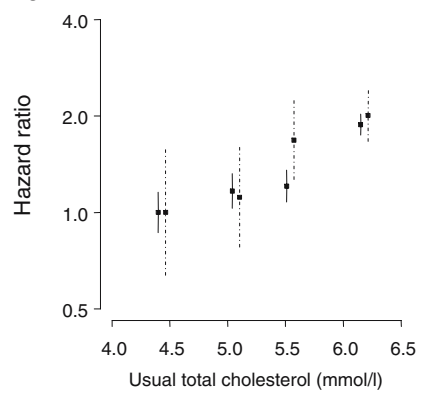

C

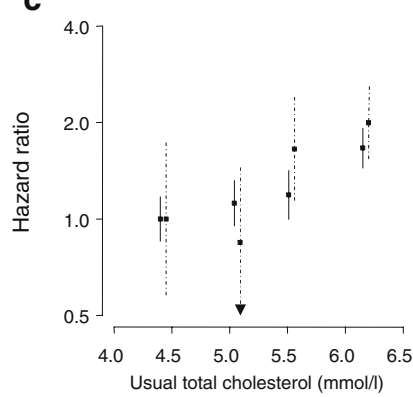

b
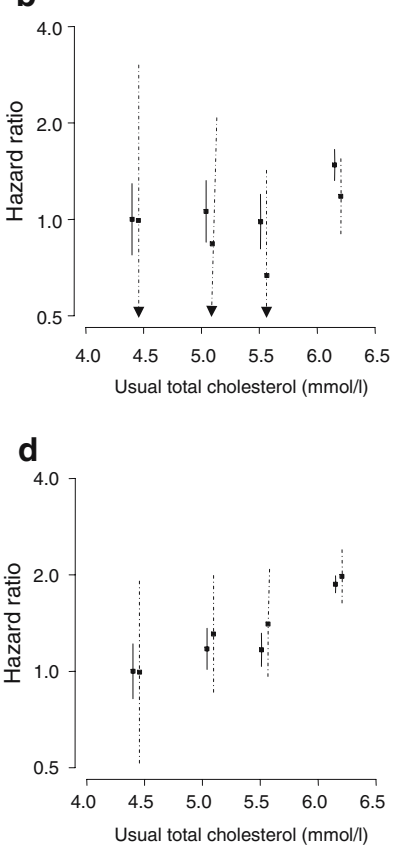

Fig. 2 Association between usual total cholesterol and CHD events by baseline diabetes status for a men, b women, $\mathbf{c}$ cohorts from Asia and $\mathbf{d}$ cohorts from ANZ. The HR for the lowest fourth of total cholesterol was fixed at 1.0 separately for those with and without diabetes. Analyses were adjusted by age and stratified by study and sex. $p=0.84$ (a), $p=0.41$ (b), $p=0.78$ (c) and $p=0.67$ (d) for heterogeneity of the association of total cholesterol and major outcomes by diabetes status. Dashed lines, 95\% CI with diabetes; continuous lines, $95 \%$ CI without diabetes; arrowhead, lower 95\% CI spans beyond the $x$-axis
Sensitivity analysis Two of the studies included (KMIC in Asia and Busselton in ANZ) contributed 3,214 (52.3\%) of all CVD events recorded during follow-up (Table 2). After exclusion of these participants, there was still no evidence of heterogeneity in the associations between total cholesterol and each outcome between participants with and without diabetes $(p>0.17$ for interaction for all). Each $1 \mathrm{SD}$ increase of total cholesterol was associated with a $43 \%$ (95\% CI $17-75 \%$ ) and 36\% (95\% CI 26-47\%) greater risk of CHD among people with and without diabetes, respectively. The corresponding estimates for ischaemic stroke and haemorrhagic stroke were a $47 \%$ (95\% CI 6-104\%) and $29 \%(95 \%$ CI $13-47 \%)$ greater risk and a $29 \%(95 \%$ CI -34 to $62 \%$ ) and $14 \%$ (95\% CI -1 to $28 \%$ ) lower risk, respectively.

Other lipid variables and risk of CHD Data on LDLcholesterol, HDL-cholesterol and triacylglycerols were available for 62,493 participants in 21 cohorts (Table 1). For $22 \%$ of these individuals, LDL-cholesterol was directly measured rather than calculated. Mean levels of LDL-, HDL- and non-HDL-cholesterol and triacylglycerols differed significantly between those with and without diabetes. Mean (SD) values, diabetes vs no diabetes, were: LDLcholesterol 3.28 (1.10) vs 3.23 (1.05) $\mathrm{mmol} / 1, p=0.004$; HDL-cholesterol $1.30(0.41)$ vs $1.37(0.41) \mathrm{mmol} / \mathrm{l}, p<$ 0.001; non-HDL-cholesterol 3.89 (1.16) vs 3.83 (1.15) $\mathrm{mmol} / 1, p<0.001$; and triacylglycerols $1.38(\log \mathrm{SD} 0.50$ ) vs $1.20(\log \mathrm{SD} 0.50) \mathrm{mmol} / 1, p<0.001$. For each of these lipid variables, there was no evidence that the associations with CHD varied according to diabetes status (Table 3).

For stroke subtypes, there were too few events in the subset with information on lipids other than total cholesterol to perform meaningful analyses. 
Fig. 3 HR $(95 \% \mathrm{CI})$ estimates for a $1 \mathrm{SD}(1 \mathrm{mmol} / \mathrm{l})$ increase level of usual total cholesterol for CHD, ischaemic stroke and haemorrhagic stroke (Haem.), in persons with and without diabetes at baseline, by sex, region and age. Analyses were adjusted by age and stratified by study and sex, where appropriate. The $p$ values shown are for the test of interaction comparing the association between people with and without diabetes. The dashed lines/diamonds and continuous lines/diamonds represent those with and without diabetes, respectively. The horizontal lines and (for overall) the width of the diamonds are $95 \%$ CIs; the boxes are proportional to the inverse variance

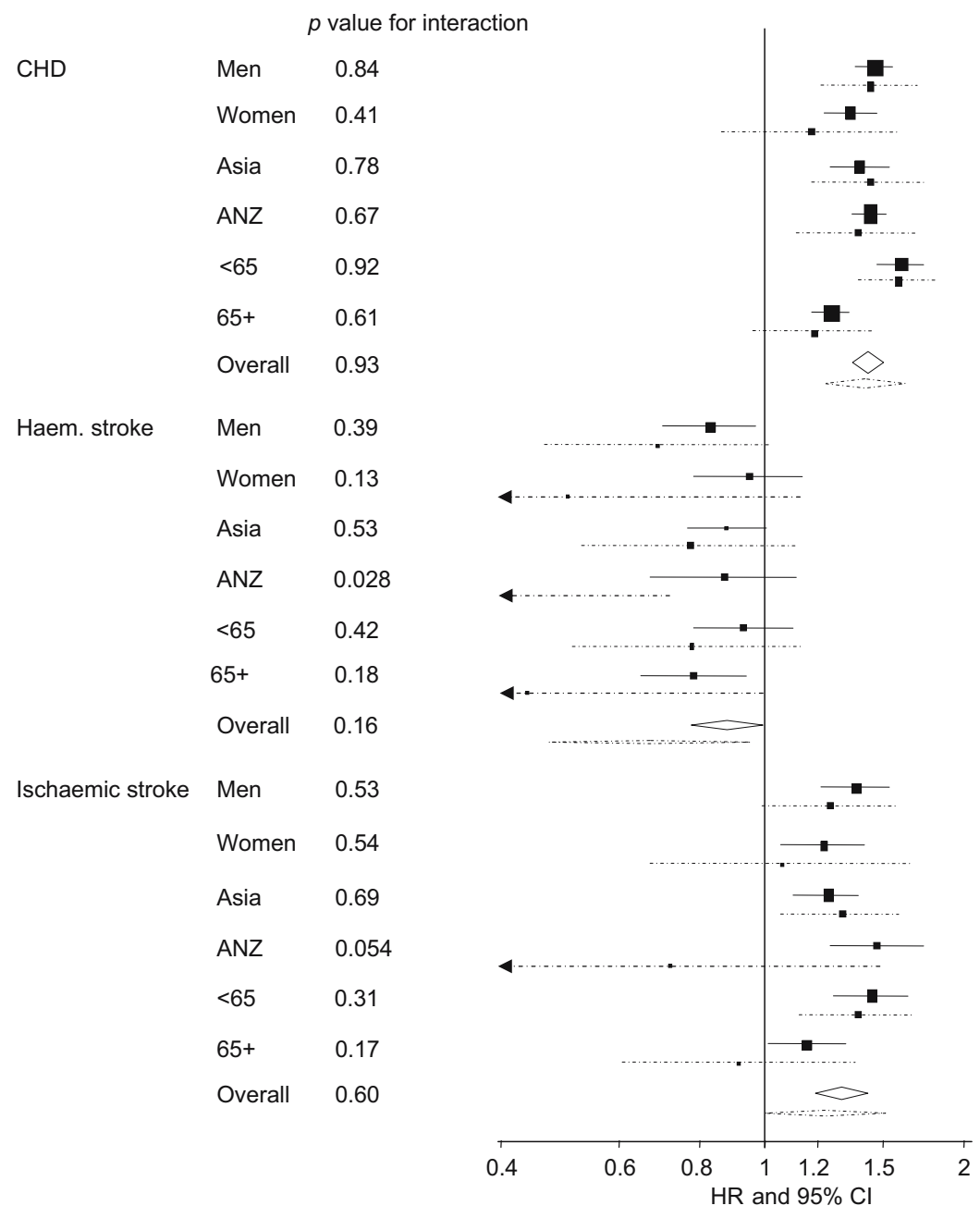

At least for CHD, there is no evidence against the same conclusion being drawn for lipids other than total cholesterol.

Relatively few studies have examined this question. Findings in those that have are inconsistent. Several analyses have reported similar associations between total cholesterol or LDL-cholesterol and cardiovascular outcomes in patients with and without diabetes $[2,4,11,12]$. However, in the

Table 3 Associations between lipid variables and risk of CHD in a subset of 62,493 individuals with recorded measures for triacylglycerols, LDL- and HDL-cholesterol

\begin{tabular}{llll}
\hline Lipid variable & \multicolumn{2}{l}{ Change in relative risk associated with 1 SD increase of variable ${ }^{\mathrm{a}}$} & \multicolumn{1}{c}{$p$ interaction } \\
\cline { 2 - 3 } & No diabetes & Diabetes & 0.40 \\
\hline Total cholesterol & $40(20$ to 64$)$ & $66(16$ to 137$)$ & 0.28 \\
LDL-cholesterol & $30(12$ to 51$)$ & $-21(-69$ to 13$)$ & 0.87 \\
HDL-cholesterol & $-25(-46$ to -7$)$ & $78(23$ to 157$)$ & 0.42 \\
Non-HDL-cholesterol & $52(30$ to 78$)$ & $39(-11$ to 116$)$ & 0.25 \\
Triacylglycerols & $84(53$ to 121$)$ & & \\
\hline
\end{tabular}

${ }^{a}$ Relative risk in \% $(95 \% \mathrm{CI})$

${ }^{\mathrm{b}}$ Change in relative risk $(95 \% \mathrm{CI})$ with $1 \log (\mathrm{SD})$ higher level of triacylglycerols 
largest analysis conducted to date [3], the relationship between total cholesterol and risk of CVD in people with diabetes was reported to be weaker than that among individuals without diabetes ( 13 vs $28 \%$ excess risk of CVD associated with a $1 \mathrm{mmol} / 1$ increase in the level of total cholesterol), although it is not clear whether this difference was statistically significant.

The current data from APCSC have several advantages compared with previous reports, including the wide range of total cholesterol levels in the population, the large number of events available for analysis, the ability to adjust for regression dilution, the capacity to examine the associations for stroke subtypes and the opportunity to compare populations with differences in the epidemiology of lipids and cardiovascular events. This is particularly important given the heterogeneity of the associations between cholesterol and stroke subtype, with a positive association observed for ischaemic stroke and a somewhat weaker, but nevertheless significant, inverse association observed for haemorrhagic stroke [13]. Recent results from the Stroke Prevention by Aggressive Reduction in Cholesterol Levels clinical trial [14] provide some support for the epidemiological data; in this trial, treatment with a statin among people with established cerebrovascular disease was associated with clear reductions in coronary events and ischaemic stroke, but was also associated with a significant excess of haemorrhagic stroke, although the number of actual events was very low, making for a highly imprecise estimate of the size of this effect. In the APCSC, individuals from Asia and those with diabetes experienced a relatively greater rate of haemorrhagic stroke than those from ANZ and those without diabetes. However, an interpretation of the public health and clinical implications of this finding must take into consideration the evolving epidemiology of CVD in the Asia-Pacific region, with a rapidly increasing predominance of atherothrombotic conditions in many areas [15-18]. For example, during the 1990s, the incidence rate of haemorrhagic stroke in China declined by an average of $12 \%$ per year, while that of ischaemic stroke increased by at least $5 \%$ per year in most regions [19]. Over a longer period in Korea, overall stroke mortality has decreased, while the proportion of deaths occurring due to ischaemic stroke and ischaemic heart disease has increased considerably [17].

There are also some limitations to our data. Some misclassification of diabetes status may have occurred due to undiagnosed diabetes and a partial reliance on self-reported previous diagnoses. Misclassification, if any, could have led to an underestimation of any true differences in the associations between participants with and without diabetes. However, the degree of misclassification would need to be substantial to change the conclusions of this study. We were unable to differentiate diabetes type in our analyses; however, the vast majority of the population is likely to have type 2 diabetes. Other potential limitations are the small number of events in some analyses of subgroups, lack of standardisation between cohorts in ascertainment of cardiovascular events, limited data available on cholesterol and other lipid variables, and the relatively high proportion of unclassified stroke events.

Nevertheless our data have important clinical and public health implications. While low levels of HDL-cholesterol and high levels of triacylglycerols are frequently observed in people with type 2 diabetes, the results indicate that the relative effects of these lipid variables are similar to those observed in individuals without diabetes, at least for CHD. These results also emphasise the importance of total or LDL-cholesterol in helping to assess the risk of cardiovascular events among people with diabetes. These findings strongly support current recommendations on lowering LDL-cholesterol to prevent atherothrombotic vascular events among individuals with diabetes. The continuous nature of the associations, as clearly demonstrated in these analyses, supports a paradigm whereby cholesterol-lowering strategies should not be primarily driven by arbitrary threshold levels of cholesterol, but rather by the absolute risk of atherothrombotic vascular events, which is generally high among people with diabetes. Our findings are consistent with the results of clinical trials [20-24] and two recent metaanalyses $[25,26]$ that suggest cholesterol lowering is associated with similar relative reductions in risk of cardiovascular outcomes among people with and without diabetes, in the context of both primary and secondary prevention. While the effects of modifying HDL-cholesterol and triacylglycerol in so-called diabetes dyslipidaemia remain uncertain [27], a continuing emphasis on total and LDLcholesterol levels in managing risk among people with diabetes remains justified.

Acknowledgements This project received support from a National Health and Medical Research Council of Australia programme grant and an unrestricted educational grant from Pfizer. The sponsors had no influence on design, analysis or interpretation of results and took no part in the writing of this paper.

Duality of interest The authors declare that there is no duality of interest associated with this manuscript.

\section{References}

1. Asia Pacific Cohort Studies Collaboration (2003) The effects of diabetes on the risks of major cardiovascular diseases and death in the Asia Pacific region. Diabetes Care 26:360-366

2. Adlerberth AM, Rosengren A, Wilhelmsen L (1998) Diabetes and long-term risk of mortality from coronary and other causes in middle-aged Swedish men. A general population study. Diabetes Care 21:539-545

3. Stamler J, Vaccaro O, Neaton JD, Wentworth D (1993) Diabetes, other risk factors, and 12-yr cardiovascular mortality for men 
screened in the Multiple Risk Factor Intervention Trial. Diabetes Care 16:434-444

4. Kannel WB, McGee DL (1979) Diabetes and cardiovascular risk factors: the Framingham study. Circulation 59:8-13

5. Pyorala K, Laakso M, Uusitupa M (1987) Diabetes and atherosclerosis: an epidemiologic view. Diabetes Metab Rev 3:463-524

6. Uusitupa MI, Niskanen LK, Siitonen O, Voutilainen E, Pyorala K (1993) Ten-year cardiovascular mortality in relation to risk factors and abnormalities in lipoprotein composition in type 2 (noninsulin-dependent) diabetic and non-diabetic subjects. Diabetologia 36:1175-1184

7. Asia Pacific Cohort Studies Collaboration (1999) Determinants of cardiovascular disease in the Asia Pacific Region: protocol for a collaborative overview of cohort studies. Cardiovasc Dis Prev 2:281-289

8. Alberti KG, Zimmet PZ (1998) Definition, diagnosis and classification of diabetes mellitus and its complications. Part 1: diagnosis and classification of diabetes mellitus provisional report of a WHO consultation. Diabet Med 15:539-553

9. Friedewald WT, Levy RI, Fredrickson DS (1972) Estimation of the concentration of low-density lipoprotein cholesterol in plasma, without use of the preparative ultracentrifuge. Clin Chem 18: 499-502

10. Easton DF, Peto J, Babiker AG (1991) Floating absolute risk: an alternative to relative risk in survival and case-control analysis avoiding an arbitrary reference group. Stat Med 10:1025-1035

11. Balkau B, Eschwege E, Papoz L et al (1993) Risk factors for early death in non-insulin dependent diabetes and men with known glucose tolerance status. BMJ 307:295-299

12. Liu J, Sempos C, Donahue RP, Dorn J, Trevisan M, Grundy SM (2005) Joint distribution of non-HDL and LDL cholesterol and coronary heart disease risk prediction among individuals with and without diabetes. Diabetes Care 28:1916-1921

13. Asia Pacific Cohort Studies Collaboration (2003) Cholesterol, coronary heart disease, and stroke in the Asia Pacific region. Int J Epidemiol 32:563-572

14. The Stroke Prevention by Aggressive Reduction in Cholesterol Levels (SPARCL) investigators (2006) High-dose atorvastatin after stroke or transient ischemic attack. N Engl J Med 355:549-559

15. Critchley J, Liu J, Zhao D, Wei W, Capewell S (2004) Explaining the increase in coronary heart disease mortality in Beijing between 1984 and 1999. Circulation 110:1236-1244

16. Zhang LF, Yang J, Hong $Z$ et al (2003) Proportion of different subtypes of stroke in China. Stroke 34:2091-2096
17. Suh I (2001) Cardiovascular mortality in Korea: a country experiencing epidemiologic transition. Acta Cardiol 56:75-81

18. Kitamura A, Iso H, Iida M et al (2002) Trends in the incidence of coronary heart disease and stroke and the prevalence of cardiovascular risk factors among Japanese men from 1963 to 1994. Am J Med 112:104-109

19. Jiang B, Wang WZ, Chen $\mathrm{H}$ et al (2006) Incidence and trends of stroke and its subtypes in China: results from three large cities. Stroke 37:63-68

20. Colhoun HM, Betteridge DJ, Durrington PN et al (2004) Primary prevention of cardiovascular disease with atorvastatin in type 2 diabetes in the Collaborative Atorvastatin Diabetes Study (CARDS): multicentre randomised placebo-controlled trial. Lancet 364:685-696

21. The J-LIT Study Group (2006) Risk of coronary events in Japanese patients with both hypercholesterolemia and type 2 diabetes mellitus on low-dose simvastatin therapy: implication from Japan Lipid Intervention Trial (J-LIT). Atherosclerosis 191:440-446

22. Collins R, Armitage J, Parish S, Sleigh P, Peto R (2003) MRC/ BHF heart protection study of cholesterol-lowering with simvastatin in 5963 people with diabetes: a randomised placebo-controlled trial. Lancet 361:2005-2016

23. Sever PS, Dahlof B, Poulter NR et al (2003) Prevention of coronary and stroke events with atorvastatin in hypertensive patients who have average or lower-than-average cholesterol concentrations, in the Anglo-Scandinavian Cardiac Outcomes Trial-Lipid Lowering Arm (ASCOT-LLA): a multicentre randomised controlled trial. Lancet 361:1149-1158

24. Pyorala K, Pedersen TR, Kjekshus J, Faergeman O, Olsson AG, Thorgeirsson G (1997) Cholesterol lowering with simvastatin improves prognosis of diabetic patients with coronary heart disease. A subgroup analysis of the Scandinavian Simvastatin Survival Study (4S). Diabetes Care 20:614-620

25. Costa J, Borges M, David C, Carneiro AV (2006) Efficacy of lipid lowering drug treatment for diabetic and non-diabetic patients: meta-analysis of randomised controlled trials. BMJ 332:1115-1124

26. Baigent C, Keech A, Kearney PM et al (2005) Efficacy and safety of cholesterol-lowering treatment: prospective meta-analysis of data from 90,056 participants in 14 randomised trials of statins. Lancet 366:1267-1278

27. Keech A, Simes RJ, Barter P et al (2005) Effects of long-term fenofibrate therapy on cardiovascular events in 9795 people with type 2 diabetes mellitus (the FIELD study): randomised controlled trial. Lancet 366:1849-1861 